\title{
Taking Authorial Stance in Arabic Research Articles Introductions
}

\author{
https://doi.org/10.33806/ijaes2000.20.2.2 \\ Hmoud S. Alotaibi and Hamed Arabi \\ Shaqra University, Saudi Arabia
}

\begin{abstract}
This study examines the linguistic resources employed by Arab academic researchers to realize the interpersonal values when introducing their research topics. It also investigates how the linguistic resources interact with the rhetorical move functions to formulate the features of effective authorial stance. Specifically, the study focuses on how the interplay of engagement resources and rhetorical move functions persuasively serves the overall argumentative writing expected in academic context. To this end, the study draws on the engagement system by Martin and White (2005) and the move structure in the CARS model by Swales (1990). The data consisted of 20 Arabic RA introductions drawn from two established journals in the field of education. The results showed an evident relation between the meanings conceived in rhetorical moves and authorial stances. The authorial stances were highly interpersonal and dialogic as most of propositions displayed linguistic features pertaining to heterogloss. Furthermore, writers tended to take assertive stance when reporting previous research findings by drawing heavily on Proclaim options, but when creating research gaps, they relied on Disclaim options. When theorizing for their studies, they, however, seemed to claim sharing views with readers through notable employment of Attribute resources. These results may raise writers' awareness of the relationship between authorial stance-taking and rhetorical move purposes, and how that is crucial for the formulation of persuasive argument endeavored in academic writing.
\end{abstract}

Keywords: appraisal, Arabic, engagement, RA introduction, stance-taking

\section{Introduction}

Writing, like speaking, entails a possible interaction between the writer and the reader (Bakhtin 1986; Thompson 2001; Hyland 2005; Bruce 2008). This notion of engagement "highlights the possibility of seeing the text not just as constructed with the readers' needs in mind, but as jointly constructed, with communicative space being left for the readers to contribute to the achievement of the text's goals" (Thompson 2001: 62). In academic and research writing, however, the requirement of engagement itself is not sufficient as additionally "there is a requirement to engaging critically" (Hood 2010: 2). Hence, constructing an authorial stance is a distinctive feature of professional academic discourse. The concept of stance refers to the ways that writers or speakers use to express their opinions about something (Hyland 2005). Hence, for the purpose of this study, stance is used to refer to the ways in which writers show their viewpoints when introducing the research study together with linguistic categories they manipulate to encode these viewpoints. 
In the genre of the research article (RA), the introduction section is the place "where knowledge is constructed in the process of text construction" (Hood 2010: 6). The knowledge construction in the RA introduction can be exhibited through move structure described in the CARS (Create a Research Space) model (Swales 1990, 2004), namely situating the study context, discussing previous works, locating a research gap, and introducing the present work. This move structure provides a space for writers to appeal, evaluate, and construct authorial voices. Therefore, the introduction section is an important part of the RA to examine authors' evaluative stances.

The main purpose of the present study is to investigate the general tendency of the Arab academic writers' authorial stance on the base of evaluative language resources they use, and how these resources associate with rhetorical move functions in introduction sections of their RAs. To this end, we draw on the Appraisal framework developed by Martin and White (2005) for analyzing linguistic resources employed by writers to show their authorial stance, and Swales' (1990, 2004) CARS model for rhetorical moves analysis. The two analytical frameworks will be briefly explained in section 1.1. In section 1.2., there will be a review of the literature, and the introduction section will be concluded by a rationale of the study and finally the research questions will be highlighted in section 1.3.

\subsection{Theoretical framework}

\subsubsection{The CARS model}

The CARS model is a framework proposed by Swales $(1990,2004)$ following his analysis of RAs in English. In his analysis, Swales identified three rhetorical moves in the RA introduction, namely establishing a territory (Move 1), establishing a niche (Move 2) and occupying the niche (Move 3). A move can be defined as "a discoursal or rhetorical unit that performs a coherent communicative function in a written or spoken discourse" (Swales 2004: 228). Each move includes at least one step which can be defined as a small unit of discourse that builds moves (Swales 1990). The main differences between the two versions of the CARS model (Swales 1990, 2004) include a) removing the step of literature review from Move 1 in the updated version because it can occur "throughout the introduction and indeed throughout the article as a whole" (Swales 2004: 227); b) adding an optional step in Move 2: presenting positive justifications; c) adding an optional step in Move 3: stating the value of the present research; and finally d) relabeling Move 3 Occupying the niche to be Presenting the present work.

\subsubsection{The appraisal framework}

The Appraisal framework is one of the three discourse semantic resources interpreting interpersonal meanings (besides Involvement and Negotiation) developed from Systemic Functional Linguistics (SFL). It is an elaborate system that enables text analysis from evaluation perspectives. Since taking authorial stance in writing is part of evaluative properties and at the heart of interpersonal meanings, this study draws on Appraisal framework to analyze the linguistic 
resources used by writers to show their authorial stance. Martin and White (2005: 40) emphasized that "Appraisal is probably most closely related to the concept of stance." It is divided into three categories: Attitude, Graduation, and Engagement (see Figure 1).

Engagement system (see Figure 2) concerns with the way writers engage with readers in the form of monogloss and heterogloss. Monoglossic engagement is single-voiced and hence non-dialogic as it does not allow for alternative viewpoints except for the writer's own. Alternatively, the heteroglossic type of engagement is multi-voiced and hence a dialogic and can be realized through expansive and contractive devices. According to Martin and White (2005), dialogic expansion opens up discussion by making authorial voice as one of possible positions. It is further categorized into two: Entertain and Attribute. In the two sub-categories, the authorial voice represents the proposition as one of possible positions, thus invokes alternative opinions. Attribute comprises two types: Acknowledge and Distance. Acknowledge is realized linguistically by wordings like He said/believes; According to.... While Distance is realized through expressions such as He claims that; It is rumored that. The second expansive category is Entertain which is usually encoded by modal auxiliaries (may, could, will, should), modal adjuncts (perhaps, probably), modal attributes (it is possible that, it is likely that), circumstances (in my view), and mental verbs (I suspect that, I think, I believe, I am convinced). With dialogic contraction, by contrast, space for discussion is limited and alternative views are ruled out. It is of twofold: Proclaim (where proposition is considered as compelling, valid and plausible) and Disclaim (where the authorial voice rejects alternative views). Proclaim has three sub-categories: Concur (realized by: naturally, of course, obviously, admittedly), Pronounce (I contend..., the truth of the matter is..., there is no doubt that...) and Endorse (show, demonstrate). Disclaim is subdivided into two domains: Deny (negation: no, not, never) and Counter (concession/counter expectation: although, but, however).

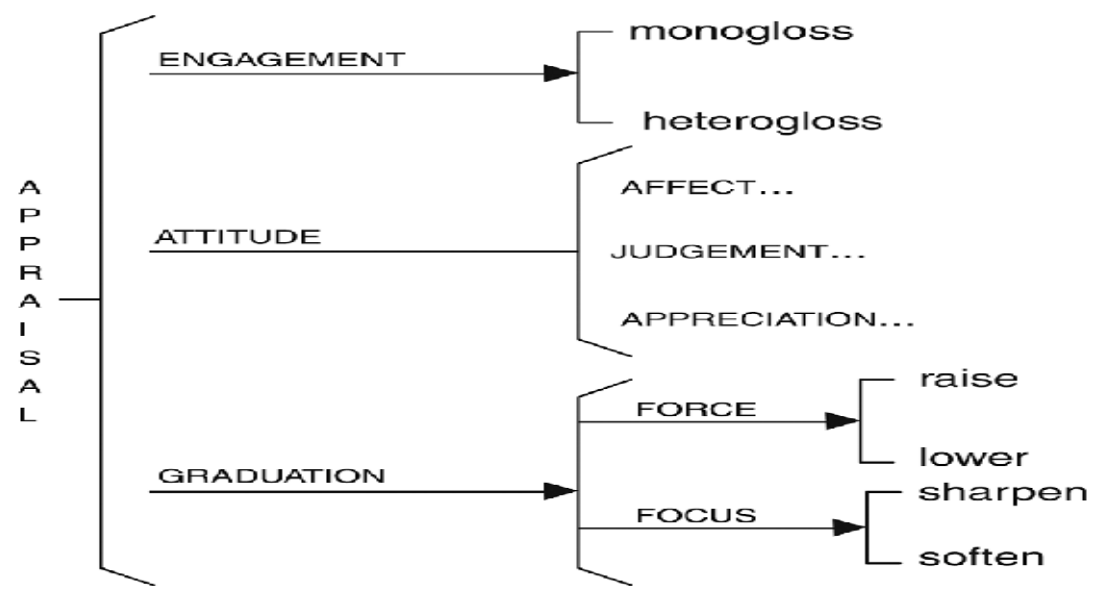

Figure. 1. An overview of Appraisal resources (Martin \& White 2005: 38) 


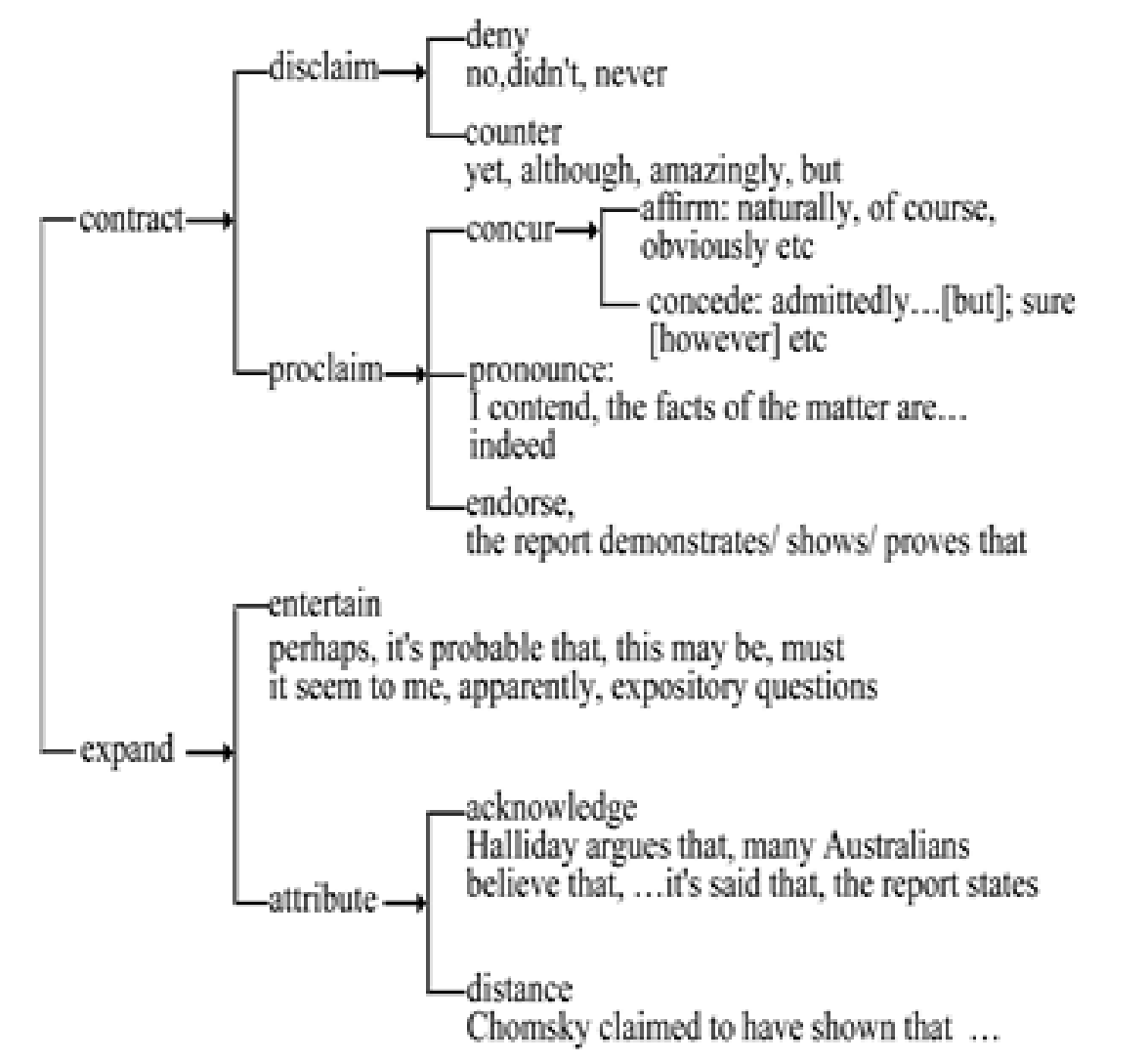

Figure 2. Engagement system: Heterogloss (Martin and White 2005: 134)

\subsection{Literature review}

In this section, a discussion of previous studies that used the Appraisal system to examine different genres will be highlighted in 1.2.1. This discussion will be followed by a review of studies that used the Appraisal system to examine the genre of the RA in 1.2.2.

\subsubsection{Studies on various genres}

The genre of spoken discourse has attracted researchers' attention to explore how Appraisal resources are implemented. For example, Ngo and Unsworth (2015) analyzed small group discussions of English and Vietnamese students. The authors provided refinements to the system of Attitude such as an extension of Judgement and Appreciation, and modifications to affect and Appreciation systems. The authors argued that their modifications "principally add delicacy to the framework and in some cases extend its comprehensiveness, so that robustness is increased and the most current version of the framework is better able to account for data in new areas of research" (Ngo and Unsworth, 2015: 22). Liu (2013) interviewed Chinese and American students to examine how both groups of speakers use the discourse markers. Specifically, the author studied the effect 
of first language on the use of English discourse markers. She found that there are three Chinese discourse markers that have influence on the use of English discourse markers. First, the Chinese speakers employed the deliberative function of I think in medial or final position. Secondly, Chinese speakers used yeah/yes as a backchannel after the interlocutor's reaction. Finally, Chinese speakers used $a h$ clause-medially. Overall, the results showed that native English speakers employed more kinds of discourse markers such as like, just, I mean, sort of/kind, while their Chinese counterparts preferred to use other discourse markers such as $I$ think and yeah/yes. Chu (2014) used the Engagement system to explore teacher talk with new arrival students at a public primary school, and particularly explored how they engage in reading and talking about children's picture books. The author found that the teacher selected certain resources and strategies to facilitate students' engagement in reading and talking about picture books. For example, "the teacher did prioritise the verbal mode over the visuals when using picture books with the students" as well as "the teacher often directed attention to the images for the purpose of preparing the students for further instructions on the verbal text" (Chu 2014: 15).

The genre of grant proposals was examined by Pascual and Unger (2010) who collected proposals that were written in English by Argentinean writers in the fields of Chemistry and Physics. The texts were found highly dialogic with an apparent focus on the use of resources in the Expand-Entertain subcategory. The overuse of these resources in this subcategory discerns that grant proposal writers tend to open up a dialogic space and thus are ready to accept and provoke other alternative views. Finally, the genre of doctoral dissertations was investigated by Geng and Wharton (2016) who used the Engagement system to explore discussion sections of theses written by L1 Chinese writers and L1 English writers. The differences between the two groups were not statistically significant. The authors commented on this result by showing that it "refutes the view that Chinese students are reluctant to critique" (Geng and Wharton 2016: 89).

\subsubsection{Studies on research articles in different languages}

Recently, there has been a growing interest in examining the authorial and evaluative stance in professional texts (e.g. Chang and Schleppegrell 2011; Cheng and Unsworth 2016; Loi et al. 2016) and in student writings (e.g. Hood 2004; Mei 2007; Wharton 2012; Xie 2016). Studies that have used the Appraisal system to investigate stance-taking in RAs have focused on the introduction (Hood 2004; Chang and Schleppegrell 2011) the discussion (Cheng and Unsworth 2016) and the conclusion (Loi et al. 2016). In Chang and Schleppegrell's (2011) study, the Engagement strategies were distributed based on the function of the organizational and rhetorical moves. For example, in the phase of preparing the study, writers employ expansive devices, mainly the Attribute, but when introducing a research gap, the contractive devices are highly present. Likewise, Hood (2004) focused on the introduction part, but with a more comprehensive approach as she compared introductory sections of undergraduate student 
dissertations to those of RAs. She found that published writers used more linguistic resources of Appreciation to evaluate findings while student writers used more resources of Affect and Judgment; thus, student writers developed a more personalized expression of evaluation compared to expert writers. The RA discussion section was found to be crucial in the study by Cheng and Unsworth (2016), who explored how writers justify the value of their research among opposing claims. They found that writers rely on the contractive options more than the expanding options, and this can be attributed to the fact that the contractive option "asserts the value of the writer's finding and confronts any contrary position directed towards this finding" (Cheng and Unsworth 2016: 49).

In contrast to previous studies that focused on English texts, Loi et al.'s (2016) cross-linguistic study examined the conclusion sections of English and Malay RAs. Their analysis showed that the critical stance was higher in frequency in the English conclusions due to the writers' "tendency to use both inscribed Attitude and Graduation evoked Attitude to assert the writer's position and perspective" (Loi et al. 2016: 12). In addition, it was found that English conclusions maintained a balance between contraction and expansion; hence, it can be interpreted as reader-friendly; while Malay texts focused more on the contracting devices, hence less reader-friendly.

\subsection{The present study}

As mentioned above, our choice of investigation falls on introduction sections of RAs by Arab writers. The rationale for this is two-fold: a) introductions are sections in which writers are expected to practice rhetorical move strategies of functional values including claiming/arguing for their own topics, proclaiming, counter-claiming other views, situating their viewpoints with others in academic contexts, etc., and b) employing these rhetorical move functions is determined by writers' success in manipulating linguistic resources to establish persuasive authorial stance. According to Swales (1990), authorial stance is more frequent in the RA introduction and discussion sections than in other sections.

Thus, in order to examine authorial stance in Arabic RA introductions more thoroughly, it will be illuminating to investigate the Engagement resources (described in the Appraisal system) to see how writers use the semantic options for expanding and contracting space for other voices. This investigation is also motivated by the absence of studies that explored the Arabic RA introductions using the Engagement system. The investigation of Engagement resources in Appraisal theory will clearly offer explanations of stance-taking and its degree in Arabic texts. Based on this rationale, the current study focuses on Arabic RA introductions using both the CARS model $(1990,2004)$ and the Engagement system in Appraisal framework. The research questions of this study are formulated as the following:

1. What is the macrostructure of the Arabic RA introductions in terms of rhetorical moves and steps?

2. To what extent do the texts employ expanding or contracting options as Engagement resources in Appraisal framework? 
3. What are the Engagement resources used by Arab writers to project their authorial stance?

\section{Methodology}

\subsection{Data collection}

The corpus used in the present study consisted of 20 Arabic RA introductions drawn from two established journals in the field of education - Journal of Educational \& Psychological Sciences (JEPS) $(\mathrm{n}=10)$, published by the University of Bahrain in Bahrain and The Journal of Educational Studies (JES) $(n=10)$, published by King Saud University in Saudi Arabia. Based on our consultation with specialists in the education field, both journals may be considered to be good representatives of research writing in the Arab world in the field of education. The reason behind selecting more than one journal is to make the data more inclusive since each journal includes publications from writers across the Arab world. The field of education was chosen because in the Arab world there are some specialized journals that publish only education-related papers. This is unlike other disciplines where they are grouped together with other related disciplines in one journal, which may cause disciplinary confusion. In addition, education is a social science that can be considered among soft disciplines which, unlike hard ones, might reflect some interesting cultural aspects, as indicated by Fakhri (2004). The articles selected for the analysis were published in 2015. The excerpts provided in this study are translated by the researchers and due to space constraints, we provided only the translated excerpts, i.e. the English versions.

Table 1 shows some basic information for the RAs selected for analysis such as the affiliation, number of issues per year, etc. Table 2 displays the size of the corpus in the selected sections, namely the Overview, the Problem of the Study, the Research Questions, the Objectives of the Study, and the Importance of the Study. Table 3 shows the number of the authors of the texts and gives some basic information of the authors. Table 4 (in the Results section) explains the employment of rhetorical moves based on the CARS model in the analyzed introduction sections, while Table 5 shows the number of Engagement resources drawn on by the writers of Introductions.

Table 1: Basic information about the selected journals

\begin{tabular}{|l|l|l|l|l|l|}
\hline Journal & Affiliation & Issue & Founded & Languages & $\begin{array}{l}\text { Peer- } \\
\text { periewed, } \\
\text { Indexed \& } \\
\text { Open access }\end{array}$ \\
\hline $\begin{array}{l}\text { The Journal of } \\
\text { Educational \& } \\
\text { Psychological }\end{array}$ & $\begin{array}{l}\text { University } \\
\text { of } \\
\text { Bahrain }\end{array}$ & 4 & 2000 & $\begin{array}{l}\text { Arabic and } \\
\text { English }\end{array}$ & Yes \\
\hline
\end{tabular}




\begin{tabular}{|l|l|l|l|l|l|}
\hline Sciences (JEPS) & & & & & \\
\hline Journal of & King & 3 & 1977 & Arabic and & Yes \\
Educational & Saud \\
Sciences (JES) & University & & & & \\
\hline
\end{tabular}

Table 2: The size of the corpus

\begin{tabular}{|l|l|l|l|l|l|}
\hline & $\begin{array}{l}\text { The } \\
\text { Overview }\end{array}$ & $\begin{array}{l}\text { The } \\
\text { Problem } \\
\text { of Study }\end{array}$ & $\begin{array}{l}\text { The } \\
\text { Research } \\
\text { Questions }\end{array}$ & $\begin{array}{l}\text { The } \\
\text { Objectives } \\
\text { of the Study }\end{array}$ & $\begin{array}{l}\text { The } \\
\text { Importance } \\
\text { of the Study }\end{array}$ \\
\hline $\begin{array}{l}\text { Average No. } \\
\text { of Words }\end{array}$ & 1704.45 & 230.35 & 95 & 57.125 & 122.83 \\
\hline $\begin{array}{l}\text { No. of } \\
\text { occurrences } \\
\text { in the texts } \\
(\mathrm{n}=20)\end{array}$ & 20 & 20 & 12 & 16 & 18 \\
\hline
\end{tabular}

Table 3: The number of authors and some basic information

\begin{tabular}{|l|l|l|}
\hline No. of Authors & Nationalities & Gender \\
\hline 9 RA= 1 author & Saudi Arabia ( 18 ) & $\mathrm{M}=17$ \\
$1 \mathrm{RA}=2$ authors & Kuwait ( 4 ) & $\mathrm{F}=15$ \\
& Bahrain ( 1 ) & \\
& Jordan (6 ) & \\
& Palestine (3) & \\
\hline
\end{tabular}

\subsection{Data coding}

After careful reading, the rhetorical moves were identified by using different colors. For example, a yellow color was used to mark Move 1 (establishing a territory), red color to mark Move 2 (establishing a niche) and green to identify Move 3 (occupying the niche). The text in each 
move was then broken down into sentences or embedded/non-embedded clauses to identify linguistic resources pertaining to the Engagement system. The text which contained linguistic resources of Engagement was written out and translated into English. Afterwards, each of the resources was underlined and the Engagement category/subcategory to which it belongs was given in brackets at the end of a sentence or a clause. The following example illustrates the process:

Despite the high rate of anxiety and depression among university students, very few of them benefit from services provided by psychological counseling centers (disclaim: counter). The majority of students do not benefit from the services and they may suffer more in terms of psychological stress (disclaim: deny + entertain).

This text was first marked with red color as it contained the rhetorical Move 2 (establishing a niche). The Engagement linguistic resources (despite, very few) were underlined and the category they belong to was provided in brackets (disclaim: counter) at the end of the sentence. When two linguistic resources were found in one sentence (as the case in the second sentence of the text above), they both were underlined with the categories being given respectively at the end. Thus, "do not benefit" and "may" were underlined, and the categories to which they belong were (disclaim: deny + entertain).

Every introduction section investigated in the present study was labeled with a separate sheet carrying the following information: the types of communicative rhetorical move (Move 1, Move 2 and Move 3), in addition to the types of Engagement linguistic resources used by the writers i.e. contracting (proclaim, disclaim) and expanding (attribute, entertain). Linguistic resources were manually counted to show which of the Engagement category was prevalent in each rhetorical move, introduction section, and in the overall corpus.

Each text was coded and was at first analyzed by the first researcher for move structure by assigning each clause with its constituent move and step. This analysis was reviewed by the second researcher. Then, the identification of Engagement resources was carried out by the second researcher and reviewed by the first researcher. These analyses were done on the RAs in their original language, and only the chosen excerpts were translated into English. Cases of differences were discussed until agreement was reached.

The first examination of the introductions selected for this study showed that all introductions include subheadings and that they were structured in the following way:

- Very long introductory paragraphs right after the abstract [Extensive Move 1 with Lit review+ Occasionally Move2 and/or Move3)

- 1st Subheading: Entitled: The problem of the study [ Move 2+ Occasionally Move 1]

In most of the introductions, the following subheadings follow the $1^{\text {st }}$ subheading.

- Research Questions [Move 3] 
- The objectives of the study [Move 3]

- The importance of the study [Move 3]

Some texts included additional subheadings such as:

- Research Hypotheses

- Research Terminology

- The scope of the study

Based on the abovementioned conventionalized subsections of the introductions, we focused our examination on a) the introductory paragraphs (and will be called Overview in this study), b) the Problem of the Study, which is the first subheading in all texts, c) the Research Questions, d) the objectives of the study, and finally, e) the importance of the study. The rest of subheadings (research hypotheses, research terminology, the scope or the study) were excluded as they appeared in a small number of texts and focused on details regarding the study and did not include authorial voice stance or possible elements of engagement.

The rhetorical moves of the CARS model were identified in all of the selected subheadings as the study aims to develop an integration of analysis to show which patterns of Engagement system are employed to achieve those rhetorical purposes. In other words, the interplay between the analysis of the rhetorical moves (based on the CARS model) and Engagement analysis (based on the Appraisal framework) is foregrounded to help finding out the extent to which the deployment of Engagement categories correlates with rhetorical moves functions.

\section{Results}

\subsection{The macrostructure of the introductions}

The move structure in the introductory paragraphs (Overview) and in all selected subheadings (the Problem of the Study, the Research Questions, the Objectives of the Study, the Importance of the Study) were examined using the CARS model (Swales 1990, 2004). As shown in Figure 3, Move 1 (establishing a territory) and Lit Review occupied most of the space in the introductions, while Move 2 (establishing a niche) was the shortest. As outlined in Table 4, instances of Move 1 were included in the Overview and a few were found in the Problem of the Study subsection. The opposite was with Move 2 where it occurred mainly in the Problem of the Study subsection and a small number of cases where located in the Overview. For Move 3 (occupying the niche), it was employed in the subsections of Research Questions, the Objectives of the Study, and the Importance of the Study, and a small number of cases were found in the Overview. The employment of moves in more than one subsection might be ascribed to the feature of move cyclicality, which was predicted in the CARS model and was seen in the previous studies (e.g., Samraj 2002; Hirano 2009; Alotaibi 2016). 


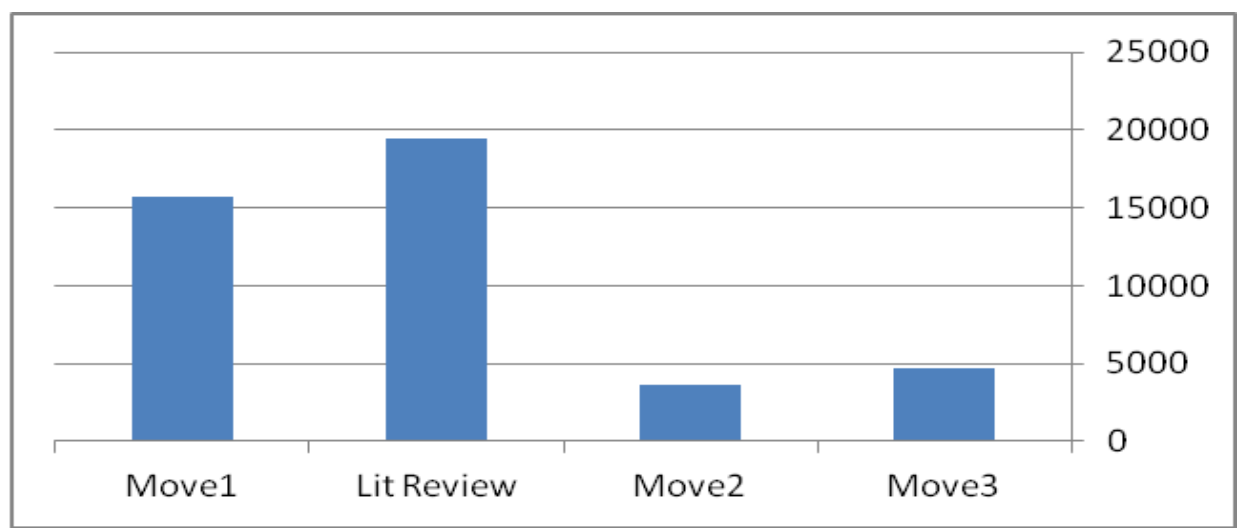

Figure. 3. Space of moves based on no. of words.

Move 1: establishing a territory; Move 2: establishing a niche; Move 3: occupying the niche

Table 4: The employment of the CARS moves in Overview and Problem of the Study subsections

\begin{tabular}{|l|l|l|}
\hline \multirow{2}{*}{$\begin{array}{l}\text { Moves in the } \\
\text { CARS model }\end{array}$} & \multicolumn{2}{|l|}{ Sections in the RA } \\
\cline { 2 - 3 } & Overview & Problem of the Study \\
\hline M 1 & $20(100 \%)$ & $14(70 \%)$ \\
\hline M 2 & $6(30 \%)$ & $20(100 \%)$ \\
\hline M 3 & $12(60 \%)$ & $4(20 \%)$ \\
\hline
\end{tabular}

The move analysis of the Overview showed that it used Move 1 and reviewed the literature. Move 1 was extensive and concerned mainly with giving background knowledge of the topic, including some instances of definitional clarifications. It cycled in the Problem of the Study subheading in 14 texts (out of 20). These instances, however, were very short and functioned in highlighting the importance of the study before the rationale of the study being underscored.

Most of the space in the Overview section was devoted to the literature review, where the predominant strategy was to separately summarize the relevant findings of each of the reviewed studies, i.e. each study was discussed in a separate paragraph. The integral form of citation (Swales 1990) was found the most predominant type. In fact, most paragraphs that reviewed the literature were opened with reporting verbs such as indicate, found, stress... (note the word order in Arabic is VSO). 
Move 2 (establishing a niche) was found roughly in half of the corpus in the Overview section, and, unexpectedly, in the Problem of the Study subsections of all texts. Most cases of Move 2 were implicit, as exemplified in (1) which was realized through the positive justification step (Step 2 in the 2004 CARS model). This move was signaled mainly through showing the dearth of studies, expressing the need for the study, problem-raising, and providing positive justifications. Some texts in the Problem of the Study subheading concluded with one or more questions. With exception to one text, the cases of question-raising in other texts were used to summarize the problem of the study and to state it clearly; hence, it should not be taken as a "step" on its own as described in the CARS model, but as a final succinct account of the problem of the study.

(1) Rapid developments of learning technologies along with recent developments in science curricula as one of cognitive economy components urged teachers to develop practical understanding of these technologies, and to use technology devices effectively when they teach. They also imposed changes in roles and jobs of teachers as real implementers of the curriculum. Since teaching is originally an interaction between teachers, students, and the courses inside or outside the classroom through different knowledge resources, teaching practices in the era of cognitive economy should be directed towards creativity, excellence, and teamwork. Based on this educational orientation, the assessment of teaching processes entails a list of criteria on which teaching practices are evaluated.

As for Move 3 (occupying the niche), roughly half of the texts in the corpus have presented the study in the Overview sections. In that section, only two steps of Move 3 were found, namely Announcing present research descriptively and/or purposively (Step 1 in the 2004 CARS model) and Stating the value of the present research (Step 6 in the 2004 CARS model). The texts that stated the value of the study ended their Overview sections with a paragraph that provided a summary of findings in previous results. The summary involved a quick comparison between the study to be presented and previous ones, and it showed that the current study tackled new issues that were not tackled in the past studies. This finding is similar to that of Anthony (1999: 44), particularly the option of novelty of the research which "is signaled in terms of differences, uniqueness, and 'extension."' In fact, this realization could be treated as positive justifications as a form of gap indications, but as argued by Samraj (2002), it may be considered statements of value since it falls in Move 3, as the case was in Anthony (1999).

Overtly, the Importance of the Study, the Objectives of the Study, and Research Questions subsections fulfilled Move 3. Presenting Research Questions (Step 2 in the 2004 CARS model) occurred in 12 texts (out of 20). The most common strategy in this subsection was to provide a list of yes/no questions and sometimes to ask questions that start with what. In a few texts, this subheading opened with a main question followed by a list of sub-questions. Generally, the 
questions preceded by a phrase such as The current study tries/seeks to answer the following questions.

The Objectives of the Study subheading, a step that was not indicated in the CARS model, was employed in 16 texts. The objectives were mostly presented in a list of bullet points, and opened with a phrase like This study aims to... followed by a gerund, mostly the word identifying.

The Importance of the Study subsection was found in 18 texts and often opened with a paragraph showing the importance or the value of the research (Step 6 in the 2004 CARS model), followed by a list of statements. In some texts, the Importance of the Study subheading resembled the Problem of the study subsection as it indicated the dearth of studies that tackled the topic. It emphasized that the study to be reported obtained its importance by being the first study to tackle that topic.

\subsection{Engagement employment in the RAs introductions}

The second major area of investigation of this study is the employment of linguistic resources to enable effective authorial stance while introducing research topics. Specifically, the study examines the engagement resources to discern how authorial stances as interpersonal meanings are expressed in the RA introductions. Table 5 displays the general findings of the engagement resources found in the texts.

Table 5: The Distribution of Engagement Resources in RA introductions

\begin{tabular}{|c|c|c|c|c|c|c|}
\hline \multirow{3}{*}{$\begin{array}{l}\text { Engagement } \\
\text { sub-systems }\end{array}$} & \multicolumn{4}{|c|}{ Heterogloss } & \multirow[t]{3}{*}{ Monogloss } & \multirow[t]{3}{*}{ Total } \\
\hline & \multicolumn{2}{|c|}{ contract } & \multicolumn{2}{|c|}{ expand } & & \\
\hline & proclaim & disclaim & attribute & entertain & & \\
\hline $\begin{array}{c}\text { No. of } \\
\text { frequency }\end{array}$ & 456 & 134 & 280 & 137 & 103 & 1110 \\
\hline Percentage $\%$ & $41.1 \%$ & $12.1 \%$ & $25.2 \%$ & $12.3 \%$ & $9.3 \%$ & $100 \%$ \\
\hline Average & 22.8 & 6.7 & 14 & 6.8 & 5.2 & 55.5 \\
\hline \multirow[t]{2}{*}{ Total } & \multicolumn{2}{|c|}{$(53.2 \%),(29.5)$} & \multicolumn{2}{|c|}{$(37.6 \%),(20.9)$} & & \\
\hline & \multicolumn{4}{|c|}{$1007=(90.7 \%),(50.4)$} & & \\
\hline
\end{tabular}

It is evident that the heteroglossic resources were employed much more than the monoglossic ones (1007 compared to 103 tokens). Within the heteroglossic network, the contracting category was more predominant in RA introductions than the expanding one, each comprised 53.2\% and 37.6\%, respectively, of all the heteroglossic resources deployed in the texts. More 
specifically, the Proclaim category was the most frequent, standing alone for $41.1 \%$. Interestingly, the most predominant sub-system within the Proclaim category was the Endorse. Regarding the expanding category, Attribute resources were more used than the Entertain.

The following excerpts highlight the linguistics resources employed by the authors to realize Engagement meanings while presenting research topics. In so doing, we can explore the prosodies of contracting and expanding, hence measure the manner and tendency of an authorial voice construed in RA introductions.

\subsubsection{Contracting resources}

As explained above, contracting is of two types: Proclaim and Disclaim. Proclaim includes the formulations which indirectly fend off or rule out contrary viewpoints; i.e. limiting the scope of dialogic alternatives (Martin and White 2005). It is further put into three sub-categories: Endorse (realized by words like demonstrate and show); Concur (encoded via: agree with, of course, certainly, not surprisingly). The third subcategory, which is Pronounce, is not found in the analyzed texts.

(2) Therefore, there is a need to improve the skills of the faculty members in employing electronic learning (contract: proclaim) and this is confirmed (contract: proclaim) by the studies of Ashoor (2009), Al-Dibyan (2011), and Abu-Khatwa (2012). Electronic training is defined as a nontraditional active training system that depends on using internet sites in a way that helps communicating information to trainees (Abdal-Razig, 2011) (attribute). [...] Several research studies demonstrated the importance of electronic training programs (contract: proclaim). An example of this was the study by Samuels and Kirk (2006) whose findings showed low training costs due to using internet networks (contract: proclaim).

The writers in (2) employ the contracting-Endorse options when reviewing the findings of prior research studies. For example, they endorse the importance of electronic training programs and the low costs due to using internet networks by employing the reporting verbs demonstrate and show, respectively. By such Endorsing formulations, the propositions are presented as true and valid. The lexical categories demonstrate and show represent the authorial voice as setting itself against opposing external voices, hence construed as dialogically contractive. In other words, they close down the space for dialogic alternatives rather than open it up.

It is worth noting here that more than $64 \%$ of such contracting options are associated with the rhetorical move of literature review, which may imply that the authors of Arabic introductions take for granted the reported previous research findings leaving less or no space for discussion.

Disclaim is another contracting option that directly rejects contrary dialogic alternatives. It falls in two subcategories: Deny, which is achieved via negation 
lexical categories like not and never, and Counter, which is realized by concession and counter expectation words such as although, but, however. The following excerpt (3) elucidates the Disclaim strategy.

(3) Despite the high rate of anxiety and depression among university students, very few of them benefit from services provided by psychological counseling centers (disclaim: counter). The majority of students do not benefit from the services and they may suffer more in terms of psychological stress (disclaim: deny + entertain). There is, therefore, an urgent need for guidance and preventive programs for all students (contract: proclaim).

The author seems to pave the way for stressing the importance of the topic by indicating some faults and inadequacies in the findings of previous studies. To do so, the writer employs Disclaiming strategies reflected in the use of the counter-expectation proposition (Despite the high rate of ...) to show that only a small number of suffering students benefited from psychological counseling centers. Then, the author uses another Disclaiming option (the majority of students do not benefit from these services) to deny the sufficiency of services offered by the psychological counseling centers. Depending on such successive Disclaiming options, the researcher directly and assertively rules out any potential contrary alternatives, hence leaves no space for discussion. Furthermore, by concluding with a Proclaim strategy in (There is, therefore, an urgent need for guidance and preventive programs for all students), the author is clearly establishing a niche for his study. It is worth noting that Disclaiming resources in this study are comparatively more frequent in Move 2 (establishing a niche).

\subsubsection{Expanding resources}

As mentioned above, dialogic expansion is different from contraction in the sense that it opens up discussion rather than closes or restricts its scope. This is usually done by invoking or entertaining external alternative voices. It is further divided into two subcategories: Attribute and Entertain.

According to Martin and White (2005), Attribution is the process in which the authorial voice dissociates itself from the proposition by attributing it to other external voices. This is often realized through grammar lexemes of direct and indirect speech as (X says, $\mathrm{X}$ claims, according to $\mathrm{X}$, in $X^{\prime}$ 's view, etc.). The results have shown that the Attribute options are associated more predominantly with Move 1 (establishing the territory), specifically with the propositions in which writers provide definitional and explanatory clarifications to back up arguments for their own research topics. In the following part of discussion in (4), we offer an excerpt from the analyzed texts where Attribute resources are employed.

(4) Anthropometric measurements play a significant role in the physical sports field through their association with many kinetic abilities and excellence in different activities (monogloss) [...] Hasanein (2003) states the importance of anthropometric measurements in predicting what results can be achieved (expand: attribute), as these measurements are 
considered (expand: attribute) one of individual characteristics that have a correlation relationship to achieve high levels of sports and providing opportunity of excellence. Many studies have focused on providing information about the physical fitness and characteristics of the human body. Jawad (2004) adds that physical measurements should be taken into consideration when selecting the sports player (expand: attribute).

Here, the writers discuss the importance of anthropometric measurements in sports. They begin with taken-for-granted information that is presented through monoglossic proposition in the first sentence. They then take the importance of anthropometric measurements as an agreed upon issue that does not need to be discussed. Yet, when the authors look for evidential theories to support their argument, they drew on Attribute options in the second sentence by making reference to an outside source. Furthermore, this choice reflects impersonal stance where writers chose to engage their textual voice dialogically and interactively with external one.

The second expanding subcategory is Entertain which is used to dialogistically open up discussion by allowing other alternatives into texts. The writer considers his/her authorial voice as one of other possible voices and viewpoints. Entertaining meanings are usually encoded in modal auxiliaries (may, might, could), modal adjuncts (probably, perhaps), directives and modality of permission or obligation (must, should, would). The following excerpt illustrates an Entertaining resource employed by the writers.

(5) The study also used the method of multiple linear regression analysis, and it found that the admission selection grades and the total grades in the general secondary school certificate are generally considered the most important predictor of success, and that the student's specialization may affect this success. (expand: entertain)

The author in (5) reports the findings of a previous research study that are relevant to the topic of his own research. He begins with explaining the analytical method (linear regression analysis), then shows the result. Reporting the first part of the result, the writer uses an Attribute-acknowledge resource (are considered the most important...), which may imply his agreement with it. However, when he comes to introduce the second part of the result (the student's specialization may...), the author employs one of Entertaining resources (modal auxiliary may). In doing so, he considers his authorial voice as one possible viewpoint. In other words, the writer does not confirm that "the student's specialization affects the success," rather he takes the student's specialization as one of possible matters affecting this success. The writer therefore invites and negotiates the matter with other alternative viewpoints leaving some space for discussion.

(6) The psychology Association of Mathematics Education (PME) emphasizes the relationships between spatial capabilities and learning engineering concepts by visual methods. Silverman (2011: 3) confirms the use of computers to develop the ability of spatial visualization. Clements and Sarama (2005: 56), also, indicate that the engineering and 
mechanic relations should be learned by means of body movements. (expand: entertain).

In a similar way as above, the authors in excerpt (6) draw on Attribute resources (PME emphasizes, Silverman, 2011 confirms...) to acknowledge the relationship between spatial capabilities and learning engineering concepts. The meaning of acknowledgement is realized through the words emphasize and confirm. In the last sentence, the writers use one of Entertaining resources should (the modality of obligation) to explain how body movements contribute to learning the engineering and mechanic relations. Although the authors begin the last sentence with another resource of Attribute (Clements and Sarama, 2005 indicate...), they do not acknowledge or confirm the body movements as important for learning engineering and mechanic relations, but rather they invite other alternative viewpoints into the text by using an Entertaining item (modality of obligation, should/would) to open up discussion.

\section{Discussion}

Based on the results above, it could be argued that the results have shown considerable employment of expanding and contracting Engagement resources. According to Appraisal theory, this tendency indicates that Arabic RA introductions are prominently heteroglossic, hence dialogistic. However, contracting resources are more frequent than expanding options which may imply that writers prefer to take assertive authorial stances when introducing their research topics. The findings also indicate that there is an overt interplay between the employment of Engagement resources and rhetorical move functions. Most of contracting options, for example, are associated with the literature review segment and less prominently with Move 3 (occupying the niche). Also, Contract-Disclaim options are found more present in Move 2 (establishing a niche). As for monogloss and expand-attribute, they are obviously dominant in Move 1 (establishing a territory) while expand-entertain resources are prevalent in Move 3 (occupying the niche).

In reporting prior research findings, the authors of Arabic texts draw heavily on the Proclaim (within contracting category) options. Being selfconfident and certain as experts in the academic field at issue, they seemingly take the previous research findings as facts and valid, thus dissociate their authorial stances with any potential contrary positions. In a similar way, the authors directly and assertively reject other alternative voices when creating gaps in the findings of the already conducted research studies by using Disclaim (within contracting category) options. This is purposively done by the authors to provide convenient conditions for announcing and applauding the research topics of their own (establishing a niche).

The two expanding categories, Attribute and Entertain, coexist with Move 1 (establishing a territory) and Move 3 (occupying the niche), respectively. This may imply that the authors acknowledge or entertain external voices while theoretically arguing for and presenting their research topics. 
In the light of what is mentioned above, it could reasonably be inferred that the authorial stances in Arabic RA introductions are assertive and less dialogic with respect to a) when reporting the findings of prior research studies and b) when creating gaps for research topics. However, they are comparatively more dialogistic a) when discussing theories pertinent to the topic and definitional clarifications and also b) when commenting on the importance and contribution of research topics. Overall, instances of assertion are more predominant than mitigation as the number of contracting resources used by the authors is bigger than expanding options.

Despite differences in objectives, the current research results reiterate the findings of Loi et al. (2016) who found that the employment of contracting resources was more frequent than expanding in RA Malay conclusions, while there was a balance of contracting and expanding resources in English conclusions. The results are also partly similar to Chang and Schleppegrell's (2011) findings where high proportions of contracting options used by second language writers were more associated with Move 2 (establishing a niche). The results bear resemblance as well to those found by Cheng and Unsworth (2016) who investigated how writers negotiate academic conflict when searching legitimacy for their new research. They report that "the construction of academic conflict in the RA discussions to negotiate the knowledge status of a novel student involves more contractive resources than expansive ones" (Cheng and Unsworth : 55). However, the present results are different from that arrived at by Pascual and Unger (2010). They found that the proposals written in English by Argentinean authors were highly dialogic as they used the Expand-Entertain resources more than other Engagement options. Yet, the differences might be associated with the nature of the data they analyzed (Chemistry and Physics), which may need further cross-disciplinary investigation in future research studies.

The high proportions of contracting resources experienced in the present study might be attributed (besides the comparatively large space devoted to where most of them are used) to two main reasons. First, the norm in Arabic written texts is that taking part in dialogue and discussion are readers' responsibility, hence, the writers may find it unnecessary to overtly entertain readers. Second, the writers of the analyzed introductions draw heavily on contracting options to show full epistemic comments as experts in the field discussed, as pointed out by Chang and Schleppegrell (2011). Furthermore, the implicit presence of critical voice in Move 2 may be ascribed to cultural norms and social legacies where criticism should not neither be scathing nor direct for the sake of maintaining rapport between discourse community members. This interpretation of criticism reluctance in the light of cultural norms is more plausible than the research competition interpretation offered in previous studies (e.g., Ahmad, 1997; AlQahtani 2006; Alotaibi, 2013).

\section{Conclusion}

The analysis of the Arabic RA introductions has shown that there is a great tendency to employ rhetorical move strategies at the move structure level. These 
rhetorical communicative strategies are found associated with considerable use of linguistic resources of Engagement system in the manner that may serve discursive writing. Relating the key findings to the research questions above, it could be said that Arab researchers' authorial stances are dialogistic as they draw much more on heteroglossic resources (contracting and expanding) than monoglossic resources. Yet, drawing much more on contracting options by the writers might render their authorial stance less critical, hence their writing becomes less reader-friendly. At macrostructure level in terms of rhetorical move, the RA introductions by Arab authors have shown instances of moves and steps most of which bear the rhetorical functions indicated in CARS model (Swale 1990 and 2004). As reported earlier, Move 1 (establishing a territory) was the longest and was associated with the Overview. Move 2 (establishing a niche) was the shortest and used in the Problem of the Study section.

To this end, the main contribution of the current study is that analyzing the written texts on the base of Appraisal system may draw writers' attention to the new strategies of construing effective authorial stance. In addition, the study shows that investigating the relationships between linguistic resources of Engagement system and rhetorical move meanings help to improve the academic researchers' insights of convincing and equally argumentative writing. This argument correlates with that by Chang and Schleppegrell (2011: 142) who found that "there is a positive relationship between the learning of stance expressions and writing performance."

Some limitations of the study need to be addressed and should be overcome in future investigations. First, the small size of corpus does not allow for broad generalizations; therefore, it is central for future studies to expand the size of the corpus. Second, the study looked into only one dimension within Appraisal theory, namely Engagement resources. Examining the three dimensions in the Appraisal framework would provide a comprehensive picture of how writers express stance in RA introductions. Finally, the study restricted the analysis to only one academic discipline, namely education, and it would be so important for future studies to examine the Appraisal resources across a range of disciplines.

Despite these limitations, the study can offer important pedagogical implications for researchers, especially L2 writers. Also, the findings can hopefully be incorporated in teaching materials of academic writing. Generally, writing pedagogy should provide more feasible instructions of how available linguistics resources can be utilized to realize the values of interpersonal meanings embedded in the Appraisal framework (Engagement categories), and then correlate them altogether with the functions of the rhetorical moves. This entails academic writing instructions to shift attention from reviewing grammatical properties of language within sentences to include how these grammatical sentences can be used to construe such interpersonal meanings as evaluative stance pursued in academic contexts. There is a general consensus among authors of previous studies (e.g. Chang and Schleppegrell 2011) that there is a need to make writers aware of connecting engagement linguistic resources with the purposes of rhetorical moves. Therefore, they need to be taught that 
every rhetorical move has particular intended meaning(s) which requires a particular engagement category and a linguistic resource realizing it. The analyzed data of the present study, for instance, show that authors draw heavily on contract devices when creating the gap in other research findings as well as claiming the significance of their own research topics. They also use considerably high degree of Attribute options (one of expanding categories) when citing theories in literature to argue for their research. Arab novice academic writers, for example, need to be exposed to Arabic wordings and expressions equivalent to English language resources used to realize Engagement options. They should equally be aware of keeping a balance between assertion and mitigation (contracting and expanding) in order to maintain dialogic and interactional relation with readers of their written texts.

Hmoud S. Alotaibi

English Language Department

College of Sciences and Humanities in Dawadmi

Shaqra University, Saudi Arabia

Email: halrwais@su.edu.sa

Hamid Arabi

English Language Department

College of Sciences and Humanities in Dawadmi

Shaqra University, Saudi Arabia

Email: hamidarabi-1965@hotmail.com

\section{References}

Ahmad, Ummul Khair. (1997). Scientific research articles in Malay: A situated discourse analysis. Unpublished doctoral dissertation, University of Michigan, Michigan, USA.

Alotaibi, Hmoud. (2013). Research article abstracts and introductions: A comparative genre-based study of Arabic and English in the fields of educational psychology and sociology. Unpublished doctoral dissertation, University of Texas A\&M University - Commerce, Texas, USA.

Alotaibi, Hmoud. (2016). 'The research gap in the introductions of Arabic research articles'. ESP Across Cultures, 13: 7-17.

Al-Mudhaffari, Musa, SupyanHussin, and Imran HoAbdullah. (2020). 'Interactional strategies in L2 writing: An exploration of hedging and boosting strategies in applied linguistics research articles'. International Journal of Arabic-English Studies (IJAES). 20 (1), 171-186. 
Al-Qahtani, Abdulkhaleq. (2006). A contrastive rhetoric study of Arabic and English research article introductions. Unpublished doctoral dissertation, Oklahoma State University, Oklahoma, USA.

Anthony, Laurence. (1999). 'Writing research article introductions in software engineering: Howaccurate is a standard model?' IEEE Transactions on Professional Communication, 42, 38-46.

Bakhtin, Mikhail. (1986). In M. Holquist (Ed.), Speech genres and other late essays.

Austin: University of Texas Press (V. W. McGee. Trans.).

Bruce, Ian. (2008). Academic writing and genre: A systematic analysis. London: Continuum.

Chang, Peichin and Mary Schleppegrell. (2011). 'Taking an effective authorial stance in academic writing: making the linguistic resources explicit for L2 writers in the social sciences'. Journal of English for Academic Purposes, 10, 140-51.

Cheng, Fei-Wen and Len Unsworth. (2016). 'Stance-taking as negotiating academic conflict in applied linguistics research article discussion sections'. Journal of English for Academic Purposes, 24, 43-57.

Chu, Celine PY. (2014). 'Supporting new arrival students' engagement with picture books: Analysis of teacher talk using the appraisal theory'. Functional Linguistics: A SpringerOpen Journal, 1 (12), 1-17.

Geng, Yifan and Sue Wharton. (2016). 'Evaluative language in discussion sections in doctoral theses: Similarities and differences between L1 Chinese and L1 English writers'. Journal of English for Academic Purposes, 22, 80-91.

Fakhri, Ahmed. (2004). 'Rhetorical properties of Arabic research article introductions'. Journal of Pragmatics, 36 (6), 1119-1138.

Hirano, Eliana. (2009). 'Research article introductions in English for specific purposes: a comparison between Brazilian, Portuguese and English'. English for Specific Purposes, 28, 240-250.

Hood, Susan. (2004). Appraising research: Taking a stance in academic writing. Unpublished doctoral dissertation. University of Technology, Sydney.

Hood, Susan. (2010). Appraising research: Evaluation in academic writing. Basingstoke, UK: Palgrave Macmillan.

Hyland, Ken. (2005). 'Stance and engagement: A model of interaction in academic discourse'. Discourse Studies, 7 (2), 173-192.

Liu, Xinghua. (2013). 'Evaluation in Chinese university EFL students' English argumentative writing: An appraisal study'. Electronic Journal of Foreign Language Teaching, 10 (1), 40-53.

Loi, Chek-Kim, Jason Lim and Sue Wharton. (2016). 'Expressing an evaluative stance in English and Malay research article conclusions: International publications versus local publications'. Journal of English for Academic Purposes, 21, 1-16.

Martin, James Robert and Peter White. (2005). The language of evaluation: Appraisal in English. N.Y. Palgrave Macmillan. 
Ngo, Thu and Len Unsworth. (2015). 'Reworking the appraisal framework in ESL research: Refining attitude resources'. Functional Linguistics: A SpringerOpen Journal, 2 (1), 1-24.

Mei, Wu Siew. (2007). 'The use of engagement resources in high- and lowundergraduate geography essays'. Journal of English for Academic Purposes, 6, 254-271.

Pascual, Mariana and Lidia Unger. (2010). 'Appraisal in the research genres: An analysis of grant proposals by Argentinian researchers'. Revista Signos, 43 (73), 261-280.

Samraj, Betty. (2002). 'Introductions in research articles: variations across disciplines'. English for Specific Purposes, 21, 1-17.

Swales, John. (1990). Genre analysis: English in academic and research settings. Cambridge, UK: Cambridge University Press.

Swales, John. (2004). Research genres: Explorations and applications.

Cambridge, UK: Cambridge University Press.

Thompson, Geoff. (2001). 'Interaction in academic writing: Learning to argue with the reader'. Applied Linguistics, 22 (1), 58-78.

Wharton, Sue. (2012). 'Epistemological and interpersonal stance in a data description task: Findings from a discipline-specific learner corpus'. English for Specific Purposes, 31, 261-270.

Xie, Jianping. (2016). 'Direct or indirect? Critical or uncritical? Evaluation in Chinese English-major MA thesis literature reviews'. Journal of English for Academic Purposes, 23, 1-15. 